\title{
"ESTUDO SOBRE A DIVULGAÇĀO DA ASSOCIAÇÃO BRASILEIRA DE ENFERMAGEM (ABEn) NO MEIO ESTUDANTIL DE ENFERMAGEM'
}

Maria Inêz Burini*

\begin{tabular}{l|l}
\cline { 2 - 2 } & RBEn/15 \\
\hline
\end{tabular}

BURINI, M.I. - "Estudo sobre a divulgaçāo da Associaçāo Brasileira de Enfermagèm (ABEn) no meio estudantil de Enfermagem". Rev. Bras. Enf.; DF, 29 : 127-157, 1976.

\section{INTRODUÇAO}

Somos testemunhas do contínuo e complexo avanço da ciência e da tecnologia que envolve o mundo e que atinge, diretamente, o setor saúde. Como parte integrante da sociedade, a enfermagem está intimamente influenciada pelos fatores de ordem econômica, social e cultural. Tal situação faz com que todos os seus problemas sejam analisados e resolvidos com base nas mudanças operadas na sociedade.

O rápido desenvolvimento da profissão em consequiência da criação de novas escolas, aumento do número de enfermeiros, de suas atribuiçōes e diversificação dos campos de atuação, leva ao aumento da responsabilidade dos enfermeiros na manutenção do nível de assistência de enfermagem, necessário à situação atual.
A preocupação dos enfermeiros em colaborar na resolução de problemas, comuns a todos, relacionados com o nível da profissão, revelou-se logo no I Congresso Nacional de Enfermagem (atualmente Congresso Brasileiro de Enfermagem - CBEn), em março de 1947, com o tema "Elaborar, em conjunto, um programa eficiente de enfermagem visando o desenvolvimento da profissão num plano elevado" (1). Os trabalhos indicaram a grande relação entre a assistência prestada ao paciente e o padrão de ensino.

Como é na escola que são despertadas as motivaçōes do futuro profissional, é nela que esperamos seja dada ênfase à responsabilidade do profissional de enfermagem na projeção de sua profissão no contexto social e à necessidade de associar-se, através das entidades de classe oficiais existentes.

(1) EDITORIAL. An. En., 16(22): 3-4, Jan-mar, 1947.

- Docente da Escola de Enfermagem da USP. - Departamento de Orientaçāo Profissional. 
BURINI, M.I. - "Estudo sobre a divulgaçāo da Associaçāo Brasileira de Enfermagem (ABEn) no meio estudantil de Enfermagem". Rev. Bras. Enf.; DF, 29 : 127-157, 1976.

A vida associativa representa a grande força das profissões que, perante à sociedade, vão se firmando através das atividades que desenvolvem.

As associaçōes de classe adquirem grande destaque pela contribuição que prestam aos órgãos governamentais, na solução dos problemas inerentes a cada profissão. Os resultados da sua atuação estão diretamente relacionados à sua organização, à interação entre seus componentes, e destes com as comunidades que constituem suas áreas de trabalho.

Em agosto de 1926, as enfermeiras do primeiro grupo de diplomadas pela Escola de Enfermagem Ana Neri, localizada no Rio de Janeiro, fundam a sua associação de classe, denominada inicialmente Associação Nacional de Enfermeiras Diplomadas Brasileiras (ANEDB), passando depois à Associação Brasileira de Enfermeiras Diplomadas (ABED) e finalmente à Associação Brasileira de Enfermagem (ABEn).

A ABEn é a única entidade de classe de caráter cultural e assistencial, representativa das enfermeiras brasileiras, em nível nacional.

Ela "...assume a responsabilidade de contribuir efetivamente para 0 desenvolvimento do ensino e do exercício da enfermagem no Pais e para o aprimoramento individual de seus membros. Ao indicar diretrizes que conduzam ao aperfeiçoamento desses programas norteia-se por crenças e princípios sólidos, fundamentais à consecução de um dos mais importantes dos seus propósitos, o de colaborar para a melhoria da assistência de saúde ao povo brasileiro.

Baseada no seu Código de tica e em seus estatutos os quais regulamentam seus fins e suas ações, e em consonância com a Declaração Universal dos Direitos do Homem, a Associação Brasileira de Enfermagem reconhece que a enfermagem, por sua natureza, tem como objetivo central o homem em sua dignidade absoluta; como atividade humana universal, rege-se por normas éticas e se desenvolve de acordo com o progresso científico e tecnológico, e, como profissão, constitui um grupo s.ocial que no contexto sócio-econômico e cultural do Pais coordena-se com as demais no sentido de contribuir para 0 bem-estar comum". (2)

Seu funcionamento dá-se por meio das Seçōes Estaduais localizadas nas capitais de quase todos os Estados da Federação. As referidas Seções podem subdivivir-se em Distritos, localizados nos municípios, onde existem núcleos de, no mínimo, dez enfermeiros.

A Diretoria é o órgão administrativo e de execução da Associação e dela fazem parte as coordenadoras das quatro Comissões Permanentes que integram atualmente a sua organização: Comissão de Assistência, Comissão de Educação, Comissão de Legislação e Comissão da Revista Brasileira de Enfermagem.

Seu órgão deliberativo é a Assembléia de Delegados constituída por delegados eleitos nas Assembléias Gerais das Seçōes; reune-se, ordinariamente, por ocasião do Congresso Brasileiro de Enfermagem (CBẼn), promoção anual da ABEn.

filiada a duas associações internacionais e uma interamericana: Conselho Internacional de Enfermagem (ICN) desde 1929; Comité Internacional Católico de Enfermeiras e Assistentes Médico-Sociais (CICIAMS) desde 1955; e

(2) Carvalho, A.C. - Política de Trabalho da Associaçāo Brasileira de Enfermagem (ABEn). Rev. Bras. Enf., 15 (1 e 2) : 146-51, Jan./abr., 1972. 
BURINI, M.I. - "Estudo sobre a divulgação da Associação Brasileira de Enfermagem (ABEn) no meio estudantil de Enfermagem'. Rev. Bras. Enf.; DF, 29 : 127-157, 1976.

Federação Panamericana de Enfermagem, desde 1969.

A estrutura da Associação Brasileira de Enfermagem (ABEn) sua amplitude de ação e o seu reconhecimento como Associação de utilidade pública (3), temlhe dado oportunidade de colaborar com órgãos administrativos, no estudo e solução de problemas relacionados à Enfermagem, defendendo os interesses gerais do membros da profissão.

Apesar de ser o único órgão representativo da classe, na liderança das atividades de caráter cultural e assistencial da enfermagem em âmbito nacional, foi constatado no relatório apresentado pela Comissão de Documentação e Estudos à Assemb!éia de Delegados do XXVI Congresso Brasileiro de Enfermagem, em 1974, o total de 17.690 (dezessete mil e seiscentos e noventa) diplomas de enfermagem expedidos até o final do referido ano (4) e no relatório da Tesouraria, o total de 3.550 (três mil e quinhentos e cinquenta) associadas quites (5).

Admitindo esta situação como não desejável à profissão e que, conforme DI LASCIO (1970) "a integração do enfermeiro recém graduado na vida profissional está diretamente relacionada com o tipo de informação que o mesmo recebeu na Escola de Enfermagem", há necessidade de se ressaltar o papel das escolas no desenvolvimento da consciência de grupo profissional de seus estudantes.

Tal fato transformou-se em preocupação da própria Associação, tendo constituído uma das recomendações do XXV
Congresso Brasileiro de Enfermagem (1973) que diz: "considerando que a associação de classe desempenha papel relevante no desenvolvimento profissional, recomenda às Escolas de Enfermagem que incluam nos currículos, assuntos e atividades programaticas relativas a propósitos, estrutura, política de trabalho e realizações da Associação Brasileira de Enfermagem" (6).

Em nível de graduação, as associações que congregam e representam universitários são o Diretório Acadêmico (DA) e o Centro Acadêmico (CA), em cujas atividades os futuros profissionais iniciam o preparo para a participação ativa em associações de classes.

A leitura das atas das reuniões do Centro Acadêmico de uma das Escolas objeto de estudo veio confirmar que, a grande maioria dos alunos que participou das atividades da associação estudantil, enquanto cursava enfermagem, fez ou faz parte do quadro social da Associação Brasileira de Enfermagem (ABEn) (7) .

OLIVEIRA (1970), preocupando-se com a formação que o aluno recebe nas Escolas de Enfermagem, relaciona a seleção de líderes, a aceitação de responsabilidades, a participação nas resoluções de problemas de elementos de grupo e o desenvolvimento da capacidade de aceitar críticas, como algumas das atividades extra-curriculares desenvolvidas pelos Diretórios Acadêmicos ou Centros Acadêmicos que contribuem para os alicerces da vida associativa.

(3) Decreto n. 31.417 de 9 de setembro de 1952, que declara de utilidade pública a Associação Brasileira de Enfermeiras Dip'omadas.

(4) MEDEIROS, N. da R.D. de - Relatório da Comissão de Documentação e Estudos da ABEn - 1974/75. Rev. Bras. Enf., 28(3) : 85-109, jul./set., 1975.

(5) IMPERIAL M.G.S.C. - Associação Brasileira de Enfermagem. Relatório da $1 .^{\mathrm{a}} \mathrm{V}^{\text {: }}$ Presidente - Presidente em exercício à Assembléia de Delegados. Rev. Bras. Enf., 28 (3) : 71-84, jul./set., 1975.

(6) RECOMENDAÇÃO apresentada no Congresso Brasileiro de Enfermagem, 25, João Pessoa, 15 a 21 de julho, 1973. Rev. Bras. Enf., 26 (1 e 2) : 349, 1973.

(7) Atas das reuniōes do Centro Acadêmico XXXI de Outubro da Escola de Enfermagem da Universidade de São Paulo. 
EURINI, M.I. - "Estudo sobre a divulgaçāo da Associaçāo Brasileira de Enfermagem (ABEn) no meio estudantil de Enfermagem". Rev. Bras. En?.; DF, 29 : 127-157, 1976.

A própria Associação Brasileira de Enfermagem (ABEn), através da Revista Brasileira de Enfermagem, estimula a participação dos estudantes em suas atividades, mantendo a "página do estudante" desde o lançamento do primeiro número, em maio de 1932, quando era então denominada "Anais de Enfermagem".

RESENDE (1962), em seu retrospecto sobre o Histórico da Associação Brasileira de Enfermagem (ABEn) informa que, em 1946, após a formatura da primeira turma de alunos na Escola de Enfermagem da Universidade de São Paulo. por sugestão de sua Diretora D. EDITH DE MAGALHAES FRAENKEL, formou-se um elo de ligação entre a ABEn $e$ as alunas: parte da renda anual de uma de suas comemoraçōes seria destinada aos "Anais de Enfermagem" ou à própria Associação.

A partir de 1950, estimulados pelo corpo docente da referida Escola, os a.unos começaram a frequentar os Congressos Brasileiros de Enfermagem, com o compromisso de apresentarem relatórios dos conhecimentos adquiridos as suas respectivas classes.

O periodo de preparação nas Escolas de Enfermagem poderá representar uma fase decisiva na formação do espírito associativo no futuro profissional, momento no qual será esclarecido sobre o significado da Associação Brasileira de Enfermagem (ABEn) e motivado para a participação num órgão que lhe permitírá desenvolvimento sistemático e contínuo, além da possibilidade de divulgar e submeter à apreciação geral, sua própria experiência e contribuição literária.

Para ter uma visão geral das Esco'as de Enfermagem do Estado de São Paulo e diante das consideraçōes citadas anteriormente, o presente estudo se propos a saber em que momento da vida escolar e através de que meios o estudante de enfermagem toma conhecimento da
Associação Brasileira de Enfermagem (ABEn) e de suas atividades e qual sua opinião a respeito do assunto.

\section{Objetivos do Estudo}

O estudo se propõe a colher dados sobre:

1. O conhecimento da Associação Brasileira de Enfermagem e de suas atividades entre os estudantes dos terceiros e quartos anos de seis Escolas de Enfermagem do Estado de São Paulo.

2. Como foi divulgada a Associação Brasileira de Enfermagem (ABEn) e quais das suas atividades são mais conhecidas no meio estudantil de enfermagem.

3. A utilização da Revista Brasileira de Enfermagem no ensino, como recurso indispensável de aprendizado.

4. A opinião que os estudantes têm sobre a importância de associar-se à Associação Brasileira de Enfermagem (ABEn), após a formatura.

\section{Metodologia}

O Estado de São Paulo contava, no primeiro semestre de 1974, com oito Escolas de Enfermagem localizadas quatro na Capital e quatro no interior, sendo que, apenas seis possuíam o terceiro ano do curso.

\section{População}

Foram utilizados todos os alunos dos terceiros e quartos anos do Departamento de Enfermagem da Faculdade de Ciências Médicas da Pontifícia Universidade Católica (Sorocaba), da Escola Paulista de Enfermagem, das Escolas de Enfermagem da Universidade de São Paulo e Ribeirão Preto, da Faculdade de Enfermagem São José .. F Faculdade Adventista de Enfermagem. 
De acordo com o PARECER n. 163 / 72 (8) que fixa os mínimos de conteúdo e duração do Curso de Graduação em ENFERMAGEM E OBSTETRICIA, 0 quarto ano compreende as habllitaçōes que conduzem à formação do "Enfermeiro Médico-Cirúrgico", da "Enfermeira Obstétrica ou Obstetriz" e do "Enfermeiro de Saúde Pública" a partir do "Enfermeiro".

Como apenas duas das Escolas referidas anteriormente possuem as três habilitaçōes acima citadas, e para facilldade de estudo, o quarto ano fol considerado simplesmente como quarto ano.

Das outras duas Escolas, isto é, da Faculdade Adventista de Enfermagem e da Faculdade de Enfermagem São José, foram abrangidos apenas os terceiros anos, por não estar sendo seguido o PARECER 163/72, no Art. 1.0, da parte de "habilitaçōes".

Fol escolhida esta população porque nos dois últimos anos são ministradas algumas disciplinas onde, provavelmente, os alunos terão alguns esclarecimentos sobre a ABEn, além do que, estarâo mals próximos da vida proftssional e mais motivados para a participação na associação de classe.

\section{Questionário piloto}

Fol aplicado um questionário piloto (ANEXO I) em dez alunos do segundo ano de uma das escolas objeto de estudo, contendo seis questōes fechadas e cinco abertas, totalizando onze questōes.

Na avaliação do questionário aplicado pudemos constatar que: a questāo sete sobre a consulta à Revista Brasileira de Enfermagem trazia dúvidas quanto à quantificação dos termos "habitualmente" e "esporadicamente"; as questōes cinco, oito, nove, dez e onze tinham 0 mesmo objetivo, ou seja, o de investigar qual era a atitude dos estudantes em relação a ABEn; e que o conhecimento dos mesmos sobre o Centro ou Diretório Acadêmico não fol conseguido em nenhuma questão.

As modificaçōes necessárias foram efetuadas e 0 resultado das mesmas aparecem quando nós descrevemos o questionário definitivo.

\section{Método}

Fol enviada uma carta aos Diretores das seis Escolas de Enfermagem, sollcitando, além de permissão para a aplicação dos questionários, o envio de informaçōes do número de alunos existentes nos terceiros e quartos anos e o acesso aos programas de ensino de todas as disciplinas ministradas no curso de graduação.

Em data e local previamente estabelecidos, os alunos foram convocados e os dados foram colhidos através de um questionário aplicado por nós em todos os que compareceram. Os ausentes participaram do estudo apenas em algumas classes onde as professoras acompanharam o nosso trabalho e se responsabilizaram pelo envio dos questionários aplicados por elas em data posterior. Mas, mesmo apesar da boa vontade das mesmas, houve $16,74 \%$ de questionários não respondidos.

A identificação foi desnecessária e os aiunos foram orientados a não se comunicarem entre si, enquanto estivessem respondendo as questōes. Na organização do questionário foram colocadas, de inicio, três perguntas relacionadas à associação estudantil (Diretório Acadêmico ou Centro Acadêmico) com o objetivo de estabelecer uma ligação entre a mesma e a Associação Brasileira de Enfermagem

(8) BRASIL. Leis, decretos, etc. Parecer n. ${ }^{\circ}$ 163/72 C.C.R. Currículos aprovados em 28 de Janeiro de 1972. Documenta, $135: 261-4$, fev., 1972. 
BURINI, M.I. - "Estudo sobre a divulgaçāo da Associaçāo Brasileira de Enfeimagem (ABEn) no meio estudantil de Enfermagem". Rev. Bras. En?.; DF, 29 : 127-157, 1976.

(ABEn). Nas perguntas restantes foram relacionados três outros aspectos: quando os alunos conheceram a Associação Brasileira de Enfermagem (ABEn) e o que sabem de suas atividades; quando utilizaram a Revista Brasileira de Enfermagem (RBEn) e em quais as disciplinas foi indicada pelos professores, como bibliografia, e o significado de associar-se à Associação Brasileira de Enfermagem (ABEn) como profissionais e como estudantes.

Das treze perguntas, seis são abertas e sete fechadas, e o tempo que os alunos levaram para responder o questionário variou entre doze e vinte e cinco minutos.

Apesar de estarmos presentes, não houve solicitação de esclarecimentos de dúvidas que pudessem ter surgido sobre as perguntas do questionário. Limitamonos a passar uma lista de presença entre os alunos, para que pudessemos exercer um certo controle sobre o total da classe. Em geral, as ausências foram devidas ao fato de estarem fazendo a prática de campo em locais muito distantes da Escola de Enfermagem.

Quanto a análise dos programas de ensino de todas as disciplinas necessária à comprovação da presença ou ausência da Revista Brasileira de Enfermagem (RBEn) na bibliografia, houve uma grande dificuldade no estudo por não haver padronização na elaboração do referido programa mesmo dentro de cada Escola. Na Escola A, por exemplo não conseguimos sequer ver os programas, com a informação de que "não tinham o hábito de colocar a bibliografia nos programas de ensino e que todas as docentes citavam a Revista Brasileira de Enfermagem (RBEn) em suas aulas".

Na Escola E, nem todas as disciplinas faziam constar, em seus programas, a bibliografia necessária à consulta. Na Escola $\mathbf{F}$ encontramos uma lista única de bibliografia para todas as disciplinas, ministradas no curso, na qual estava incluída a Revista Brasileira de Enfermagem (RBEn).

Diante de tal evidência onde as informações só poderiam ser confirmadas em entrevista com todo o corpo docente de cada Escola, resolvemos abrir mão desse dado por não haver tempo, nem condições de realização das referidas entrevistas.

\section{Discussão dos resultados}

Os questionários de todas as classes foram enumerados e as respostas anotadas com estes números, para que pudessemos visualizar cada questionário dentro do quadro de respostas de uma mesma Escola, ou mesmo, de todas as Escolas.

Tal como foram feitos com os dados das seis Escolas, houve dificuldade na padronização dos ítens das respostas encontradas rias perguntas abertas. Daí a necessidade de ser feito, inicialmente, um quadro com todas as respostas encontradas, como é o caso da pergunta sobre as atividades da Associação Brasileira de Enfermagem (ABEn) que são conhecidas pelos alunos (QUADRO IV).

As respostas: "algumas", "maioria", "muitas", "não lembra", "quase todas" e "várias" à pergunta sobre a consulta da Revista Brasileira de Enfermagem (RBEn), estão presentes nos Quadros VIII e IX mas serão consideradas nulas.

Nas respostas da pergunta sobre os raeios através dos quais os alunos conheceram a Associação Brasileira de Enfermagem (ABEn) (QUADRO III), "Diretora" foi incluido em "professores em geral"; "comunicados" em "informativos da Associação Brasileira de Enfermagem (ABEn)", "palestras", "encontros" e "cursos da Semana da Enfermagem" em "atividades da Semana da Enfermagem", e "porteiro da Universidade de São Paulo" em "outras pessoas". 
BURINI, M.I. - "Estudo sobre a divulgaçāo da Associaçāo Brasileira de Enfermagem (ABEn) no meio estudantil de Enfermagem". Rev. Bras. En?.; DF, 29 : 127-157, 1976.

Das atividades da Associação Brasile1ra de Enfermagem (ABEn) conhecidas e enumeradas pelos alunos (QUADRO IV), "atualização", "curso de instrumentação" e "curso de atualização", foram denominados simplesmente: "cursos"; "proteção da classe", "zela pelos ditreitos" e "legislativa": "defesa da classe"; "propaganda" e "propaganda do Congresso Brasileiro de Enfermagem (CBEn)": "divulgação dos interesses da classe"; "reuniōes mensais", "reuniōes das associadas" e "reuniōes na sede": "reuniōes"; "reuniōes das enfermeiras do País": "integração de profissionais".

As respostas "consulta à Revista Brasileira de Enfermagem (RBEn", "não tenho chance", "foram barradas" e "não sei", quanto à participação estudantil nas atividades da Associação Brasileira de Enfermagem (ABEn) (QUADRO V), foram incluídas em "nenhuma".

Quanto ao método ou processo utilizado pelos professores das disciplinas mais citadas como responsáveis pela divulgação da ABEn, apenas um dos nove entrevistados informou ter usado o método de pesquisa no qual levou os alunos a fazerem um levantamento sobre a ABEn em sua própria sede, enquanto que os restantes seguiram o processo comum de preleção em sala de aula.

Os professores entrevistados da Escola A foram os da disciplina de Administração e de História da Enfermagem; da Escola B os de ttica e Legislação; os da Escola C os de ftica e História da Enfermagem; o da Escola D o de tica; o da Escola $\mathbf{E}$ o de História da Enfermagem e o da Escola $F$ o de Etica.

Ao incluirmos as perguntas referentes a associação estudantil, tivemos como objetivo relacionar o conhecimento que os estudantes têm da própria associação com o conhecimento que têm da asso- ciação profissional. Nas suas respostas constatamos que, em quatro das seis escolas abrangidas, houve disparidade quanto ao próprio nome da associação estudantil.

Na relação de finalidades do Diretório ou Centro Acadêmico, além dos 10,03\% em branco das 648 respostas, as mais citadas foram: "culturais" $(17,74 \%)$, "so_ ciais" (17,12\%), "defesa estudantil" $(16,04 \%)$, "integração estudantil" ..... $(10,64 \%)$ e "esportivas" $(9,10 \%)$.

Com as respostas "controle de enfermeiras", "promoção da profissão", "comunicação", "filantrópicas", "associativas", "promoção estudantil" e "não sei", pudemos observar que não há esclarecimentos entre os estudantes, sobre as finalidades da própria associação estudantil.

Quanto a participar ou não das atividades do Diretório ou Centro Acadêmico ,dos 338 estudantes entrevistados, $174(51,47 \%)$ responderam "não", 151 $(44,67 \%)$ responderam "sim" e 13 $(3,84 \%)$ deixaram em branco.

Tendo em vista a importância de iniciarmos a vida associativa enquanto estudantes, a situação acima citada nos mostra que os futuros profissionais não estão se preparando para participar nas atividades da associação de classe, ao contrário do que fol constatado por nós nas primeiras diretorias da ABEn, cujos membros haviam sido ativos batalhadores da associação estudantil.

Nos resultados referentes à época em que os estudantes tomaram conhecimento da ABEn, com $13,60 \%$ dos 338 entrevistados, ocorreu antes de entrar na Escola de Enfermagem e com a maioria, ou seja, $63,90 \%$ ocorreu no $1 .^{\circ}$ ano do cnrso. (QUADRO II). 
BURINI, M.I. - "Estudo sobre a divulgação da Associação Brasileira de Enfermagem (ABEn) no melo estudantil de Enfermagem". Rev. Bras. Enf.; DF, 29 : 127-157, 1976.

No QUADRO III, onde aparecem os meios através dos quais os alunos tomaram conhecimento da ABEn vamos verificar que a grande maioria cita os professores de tica $(21,44 \%)$ e de História da Enfermagem $(19,29 \%)$ como os responsáveis pela divulgação da ABEn no meio estudantil.

Tal fato poderia parecer contradição diante do quadro anterior onde os estudantes informaram ter tomado conhecimento da ABEn no 1.0 ano do curso, sendo que as disciplinas acima referidas, são ministradas, via de regra, somente do $2 .^{\circ}$ ano $\mathrm{em}$ dlante. Isto se deve a um pedido feito por nós para que colocassem na pergunta sels, somente os meios através dos quais conheceram realmente a ABEn e não quando ficaram apenas sabendo que ela existia, como é o caso da pergunta cinco.

Além dos melos acima mencionados através dos quais os alunos conheceram a ABEn, devemos citar a "Revista Brasileira de Enfermagem" $(13,06 \%)$, "informaçōes das colegas de escola" (4,28\%) e "Congresso Brasileiro de Enfermagem" $(3,31 \%)$, sendo que nenhum deles faz parte de um processo sistematizado de divulgação e esclarecimentos sobre a Associação Brasileira de Enfermagem. A Revista poderia sê-lo, mas é consultada apenas quando o professor pede que algum assunto de Enfermagem Médica, Cirúrgica, ou de outra disciplina, seja alí procurado.

Conhecer a ABEn através do Congresso, só poderia ser pelo decorativo cartaz que é afixado nas escolas ou pela movimentação do corpo docente preocupado em elaborar trabalhos ou em planejar suas atividades de maneira que possam deslocar-se até onde o Congresso será reallzado.
Talvez ao se referirem ao Congresso como meio através do qual conheceram a $A B E n$, estivessem querendo dizer que era uma de suas atividades, pois, no QUADRO IV referente às mais conhecidas, das 40 listadas, "Congresso Brasileiro de Enfermagem" obteve maior número de respostas $(22,13 \%)$.

As outras atividades mais citadas foram "Revista Brasileira de Enfermagem" $(18,53)$ e "cursos" $(10,26 \%)$, sendo que as restantes não obtiveram porcentagem significativa.

Era esperado por nós que o Congresso obtivesse tão grande número de respostas devido à ampla divulgação que existe em torno do mesmo, assim como esperávamos que a Revista fosse citada devido a ser uma das duas únicas e mais antiga revista especifica de enfermagem e que deveria ser consultada e indicada por todos os docentes das Escolas de Enfermagem.

Quanto aos cursos, a tendência está em, cada vez mais, dar oportunidade de participação aos estudantes, ao mesmo tempo que atualiza os profisisonais.

O QUADRO IV fol elaborado com todas as respostas dos alunos para que pudéssemos visualizar o quão evidente está o fato de que a ABEn não se faz conhecer através de suas atividades e de que existe uma visão distorcida sobre o que é a nossa Assucliação (como por exemplo "distribuição de empregos", "apresentação de trabalhos em congresso", "Conselho Federal de Enfermagem").

Das atividades da ABEn (QUADRO V) os alunos participam mais das Jornadas $(6,31 \%)$, dos cursos $(5,49 \%)$ e dos "Congressos" $(3,84 \%)$, o que vem reforçar as mais divulgadas. A participação nos Congressos, pelos alunos, se dá há muito tempo, mas nos últimos anos, os que estão no final do curso, estão demons- 
BURINI, M.I. - "Estudo sobre a divulgação da Associação Brasileira de Bnfermagem (ABEn) no melo estudantil de Enfermagem". Rev. Bras. Enf.; DF, 29 : 127-157, 1976.

trando mais interesse em se familiarizarem com a integração profissional que se dá, infalivelmente, durante os trabalhos desenvolvidos no congresso. Existe também a oportunidade de integração estudantil, visto que os alunos de quase todas as Escolas de Enfermagem do país se fazem representar e que fazem absoluta questão de se reunirem para trocar experiências relativas à sua Escola de origem.

Outro aspecto que deve ser notado no QUADRO V é que "Semana da Enfermagem" obteve apenas $1,64 \%$ de participação dos estudantes, sendo que, via de regra, a programação estudantil dessa semana é feita concomitante à programação dos profissionais.

A pergunta "pretende participar de alguma atividade da ABEn futuramente" (QUADRO VI) fol introduzida com o objetivo de colher mals dados relativos a como os alunos encaram a sua futura associação de classe. Dessa pergunta, a porcentagem de "não" (7,69\%) e de votos "em branco" (15,97\%) fol significativa a ponto de podermos registrar que a ABEn precisa melhorar a divulgação e a imagem que suas atividades têm no meio estudantil. Será que entre os profissionais se dá a mesma coisa?

Quanto ao conhecimento da Revista Brasileira de Enfermagem (QUADRO VII), a grande maioria $(97,92 \%)$ respondeu conhecê-la, embora não a tivessem citado entre as atividades anteriormente listadas (QUADRO IV).

Pudemos observar que dentre as disciplinas que indicam a Revista Brasileira de Enfermagem como bibliografia, "Ad- ministração aplicada à Enfermagem" foi a mais citada $(14,38 \%)$, vindo em seguida "Fundamentos de Enfermagem" (12.30\%), "Enfermagem Cirúrgica" $(10,11 \%)$ e “tica” (10,01\%).

As baixas porcentagens das outras disciplinas restantes vem confirmar o fato verificado anteriormente por nós que as docentes responsáveis pelos programas de ensino, não têm o hábito de "colocar as bibliografias nos mesmos", ou não "colocam a Revista na bibliografia, mas citam-na em classe".

Formar no aluno o hábito de consultar sistematicamente a Revista Brasile:ra de Enfermagem deveria ser parte dos objetivos de todas as disciplinas ministradas no curso de enfermagem, para que o mesmo pudesse, além de adquirir conhecimentos técnicos, aprender a valorizar e conhecer a enfermagem do seu pais.

No QUADRO IX podemos ver que, além das disciplinas nas quais a Revista fol indicada como bibliografia, existe outra na qual, embora não conste no quadro anterior, a Revista foi consultada pelos alunos. "Enfermagem Médica" com $9,98 \%$ das respostas, além das maiores porcentagens que são correspondentes às quatro disciplinas onde a Revista fol indicada. Mais uma vez tornase evidente que o professor tem importante papel na formação do nosso profissional.

A pergunta 12 sobre se o aluno estaria ou não interessado em associar-se à ABEn enquanto estudante, surgiu da idéia de que os alunos estavam querendo fundar uma Associação Estudantil, nos 
BURINI, M.I. - "Estudo sobre a divulgaçāo da Associaçāo Brasileira de Enfermagem

(ABEn) no melo estudantil de Enfermagem". Rev. Bras. Enf.; DF, 29 : 127-157, 1976.

moldes da ABEn, e dos 338 questionários respondidos, $289(85,50 \%)$ responderam "SIM".

Dos 14,49\% que responderam "NAO", os motivos foram os seguintes: "falta de tempo", "dificuldades financeiras", "falta de atividades para o aluno", "não assistência às reuniōes", "desconhecimento" e "falta de motivação".

Dos que respoderam "sim" (QUADRO $\mathrm{X})$ as razōes mals citadas foram: "atualizaçāo" (29,42\%), "Integração" (14,98\%) e "participação nas suas atividades" $(12,34 \%)$, razöes essas que se fossem suficientemente esclarecidas e valorizadas pelo corpo docente aos alunos, teríamos atualmente maior número de associados e a profissão mals desenvolvida e acreditada.

O momento de saber se os alunos realmente acreditam na ABEn pelo pouco que sabem da mesma chegou com a questāo referente a se eles associar-seiam à ela depois de formados (QUADRO XI). Houve "sim" (86,98\%) e houve "nāo" (4,73), que fol justificado por "desconhecimento". Apesar de ser uma porcentagem pequena, os "talvez", "não sel" e "em branco" (num total de 8,28\%), poderāo estar aí incluídos, e por isso n!erecem uma atenção especial.

Na realidade o "desconhecimento" apareceu em todo o trabalho e é onde nos fixaremos quando escrevermos as consideraçōes finais.

Os "sim" foram justificados (QUADRO XII) de maneira semelhante ao do QUADRO $\mathbf{X}$, e as respostas que obtiveram malor porcentagem foram: "atualização" (38,02\%), "integração" (12,23\%) e "promoçāo da profissāo" (10,41\%).

\section{Conclusōes e Recomendaçס̃es}

1) Considerando que a maioria dos alunos de seis Escolas de Enfermagem do Estado de São Paulo tomaram conhecimento da ABEn por meio do Congresso, da Revista Brasileira de Enfermagem e por melo dos professores de Administração aplicada à Enfermagem e História da Enfermagem, e que as atividades mais citadas pelos alunos foram o Congresso, os cursos e a Revista, recomenda-se:

a) à ABEn que mantenha um processo sistematizado de divulgaçāo das suas atividades junto às Escolas de Enfermagem, e

b) ìs Escolas de Enfermagem que d1vulguem as atividades da $\mathrm{ABEn}$, através das docentes de todas as disciplinas.

2) Considerando que das atividades da ABEn os alunos apenas participam dos cursos e dos Congressos, recomendase às Escolas de Fnfermagem que estimulem a participaçāo desses nas demais atividades da ABEn que tenham acesso.

3) Considerando que a Revista Brasileira de Enfermagem foi indicada como bibliografia em Administração aplicada à Enfermagem, Fundamentos de Enferfermagem e Enfermagem Médica (segundo a maior porcentagem das respostas) recomenda-se às Escolas de Enfermagem que estimulem o corpo docente a se utilizar da Revista como recurso indispensável de aprendizado.

4) Considerando que os estudantes responderam "ser associados à $A B E n$ enquanto profissionais significa atualização, integração e promoção da profissão", recomenda-se que a Associação lance mão desses aspectos para estimular a desão de novas assocladas. 


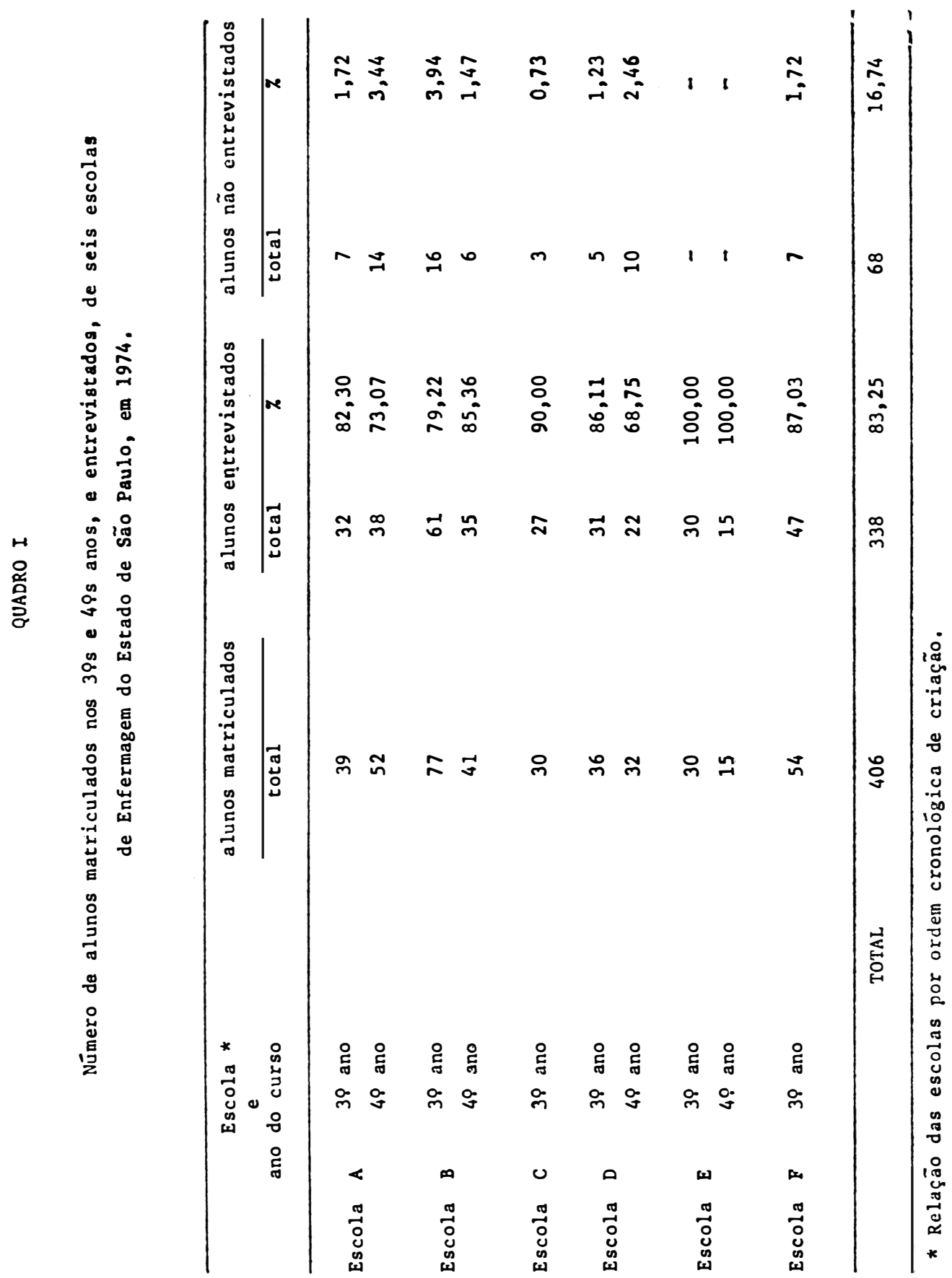




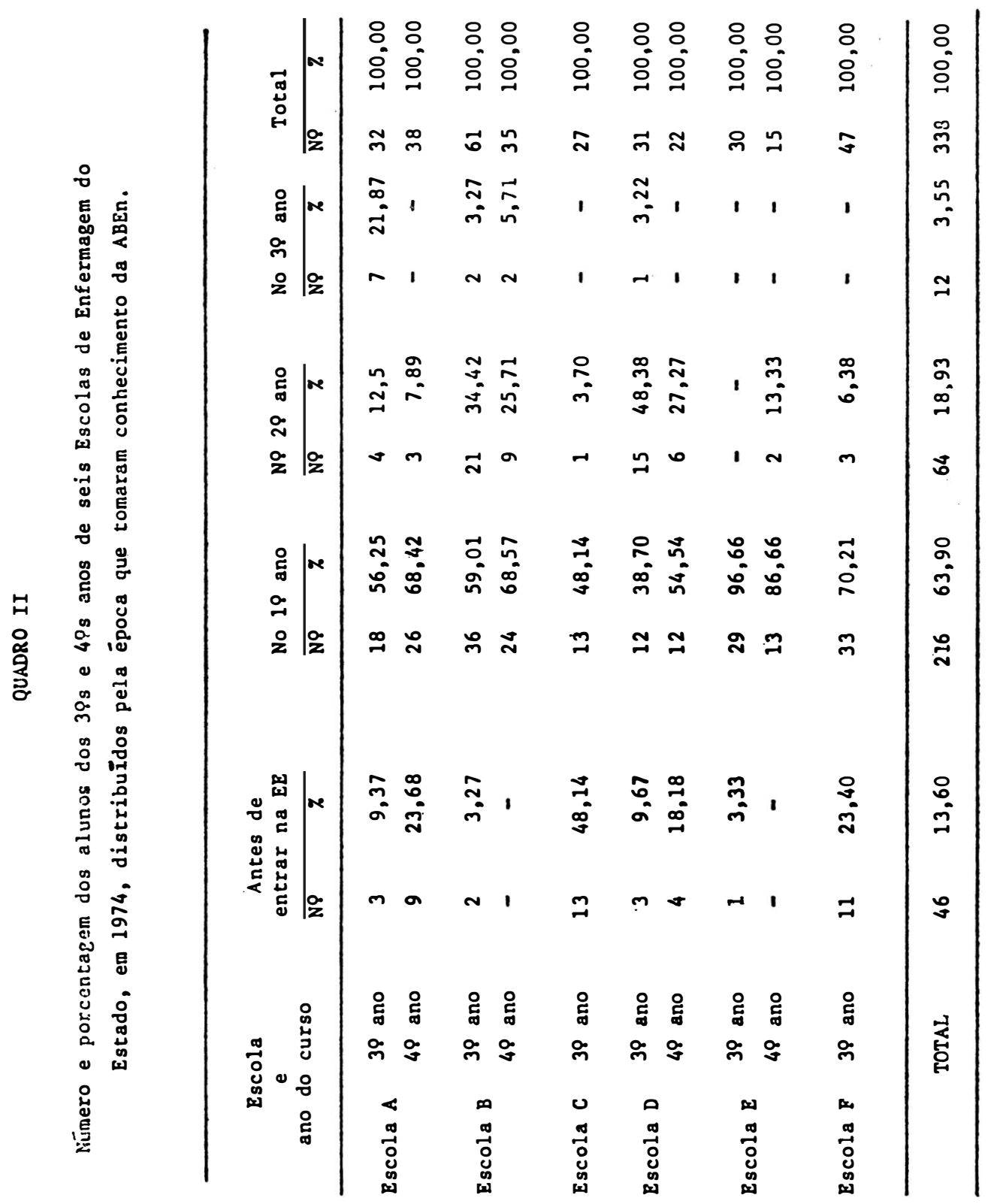




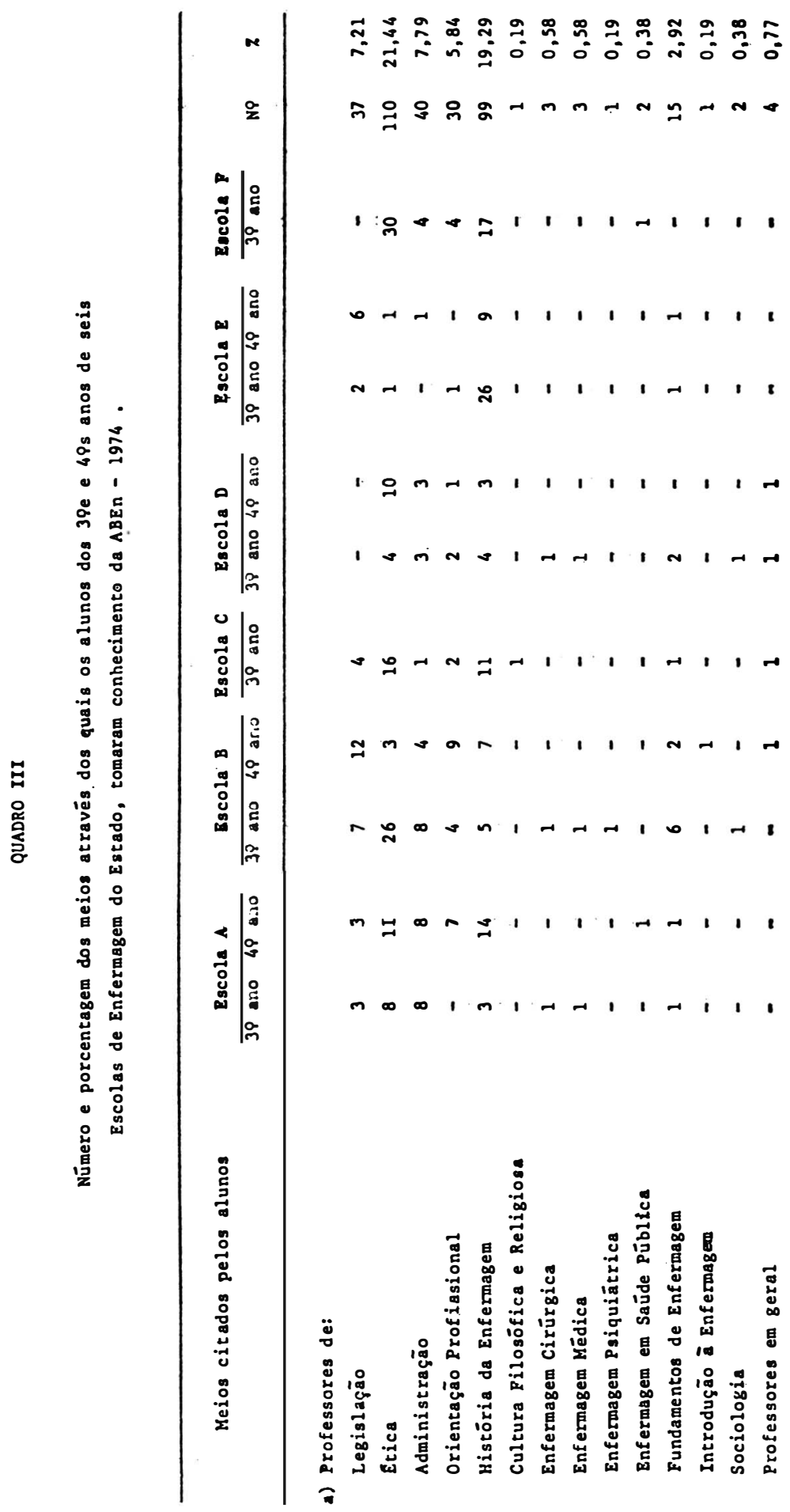


BURDN, M.I. - "Estudo sobre a divulgaçāo da Associação Brasileira de Enfermagem (ABEn) no meio estudantil de Enfermagem". Rev. Bras. Enf.; DF, 29 : 127-157, 1976.

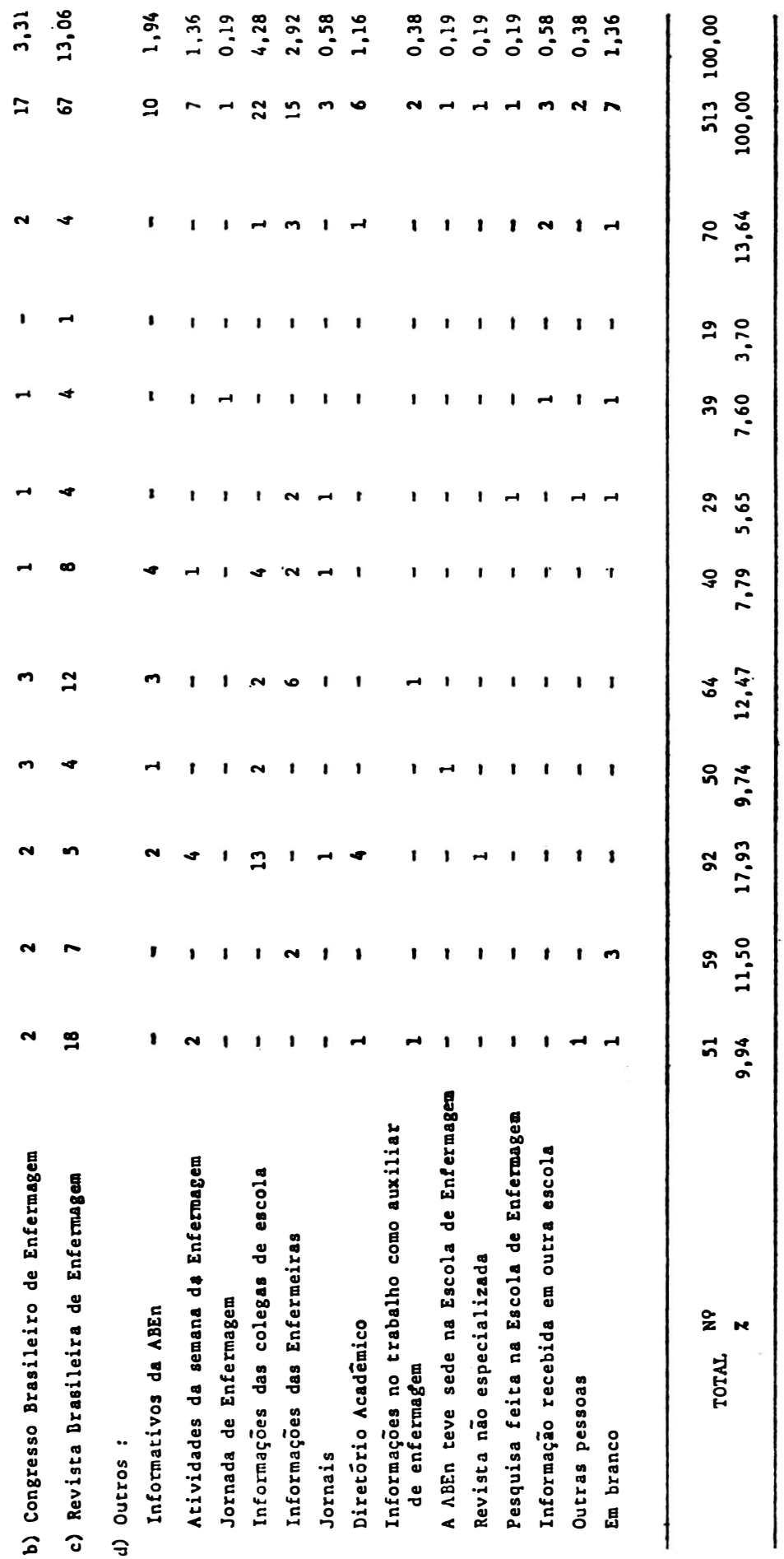




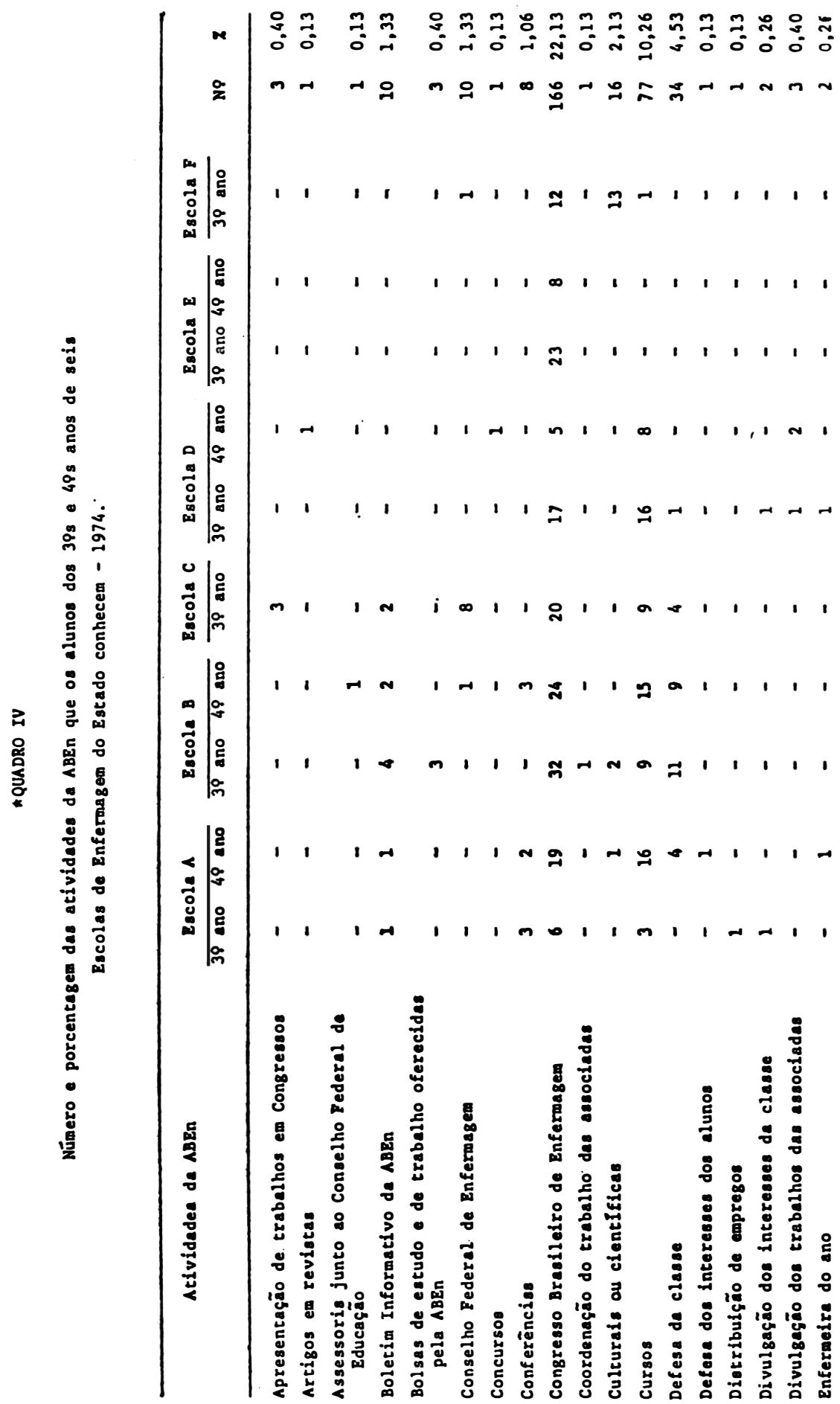




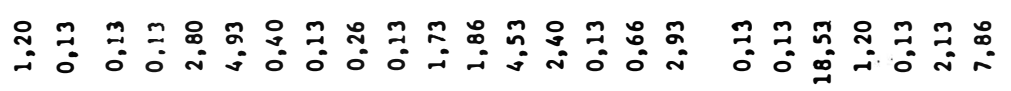

a 1 - -

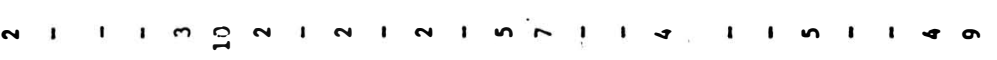

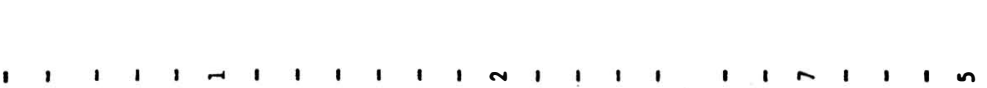

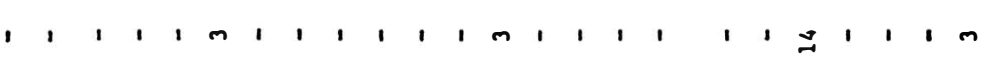

i

$\div \underset{0}{0}$

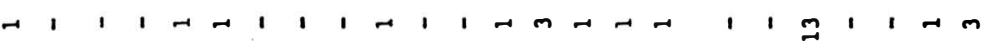

$\approx 8$

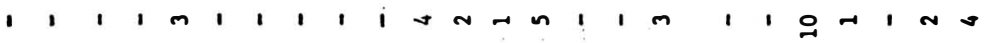

$\approx$

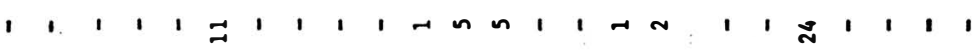

$\approx \stackrel{0}{2}$

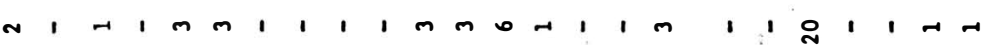

กั

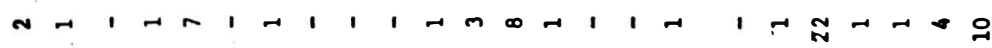

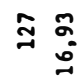

$n, 1, \Delta \infty \quad 1,1,-m-1, m n-1=m, 1 \infty$

\&

$1,111,1+1,1-1,1,10110010$

กั

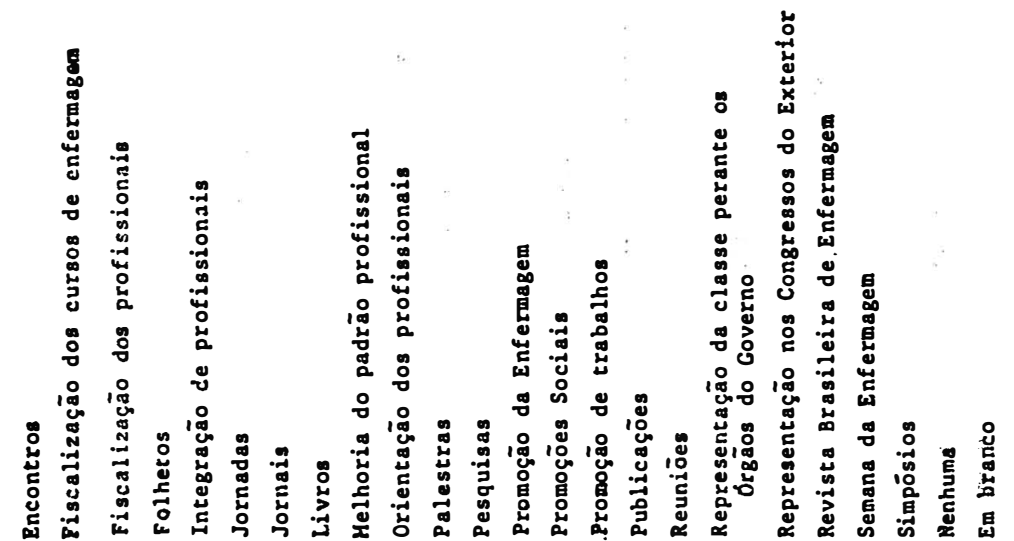

론 
BURINI, M.I. - "Fstudo sobre a divulgaçåo da Assoclaçåo Brasileira de Fnfermagem (ABF) no melo estudantil de Enfermagem". Rev. Bras. Enf.; DF, 29 : 127-157, 1976.

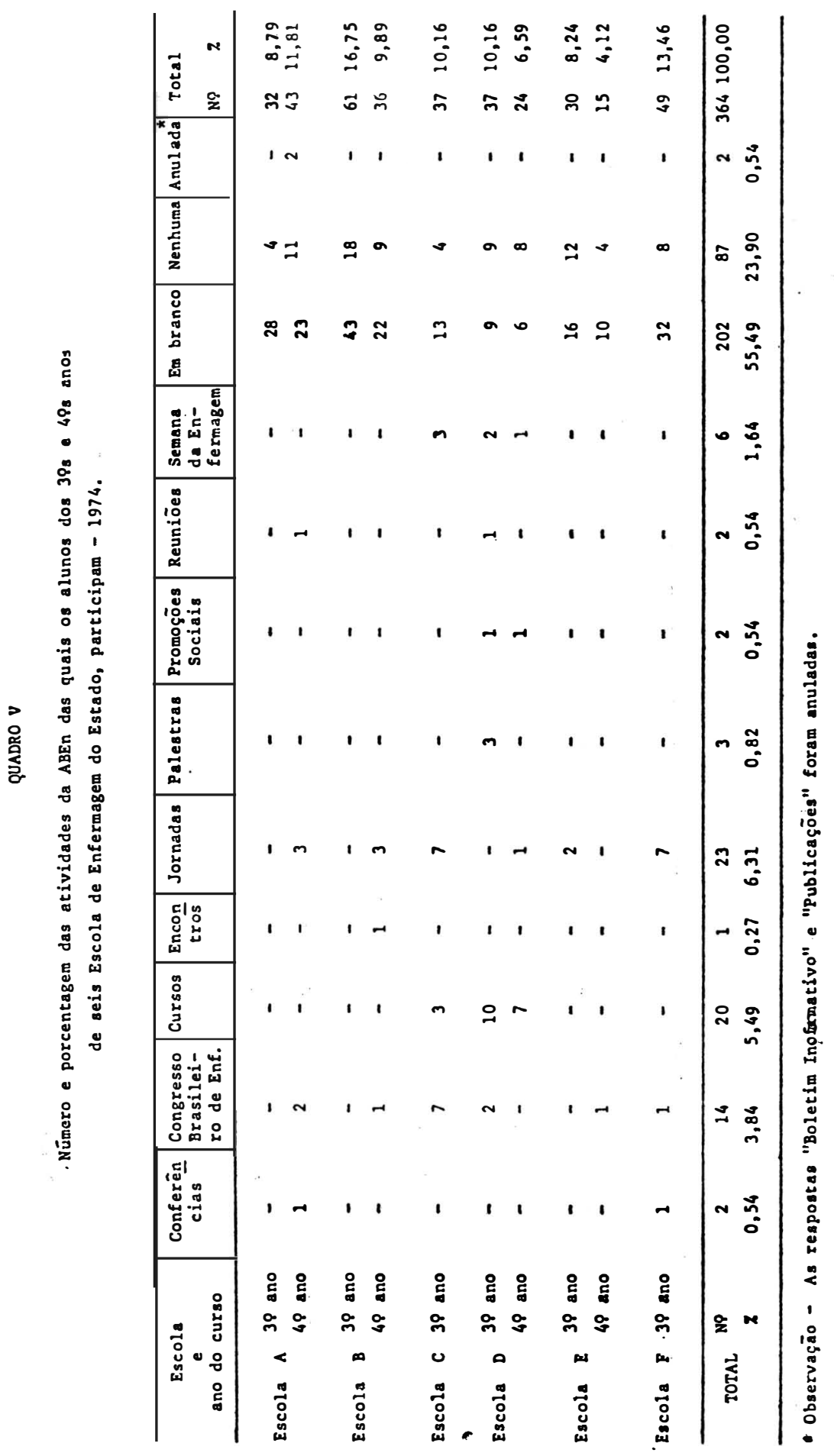




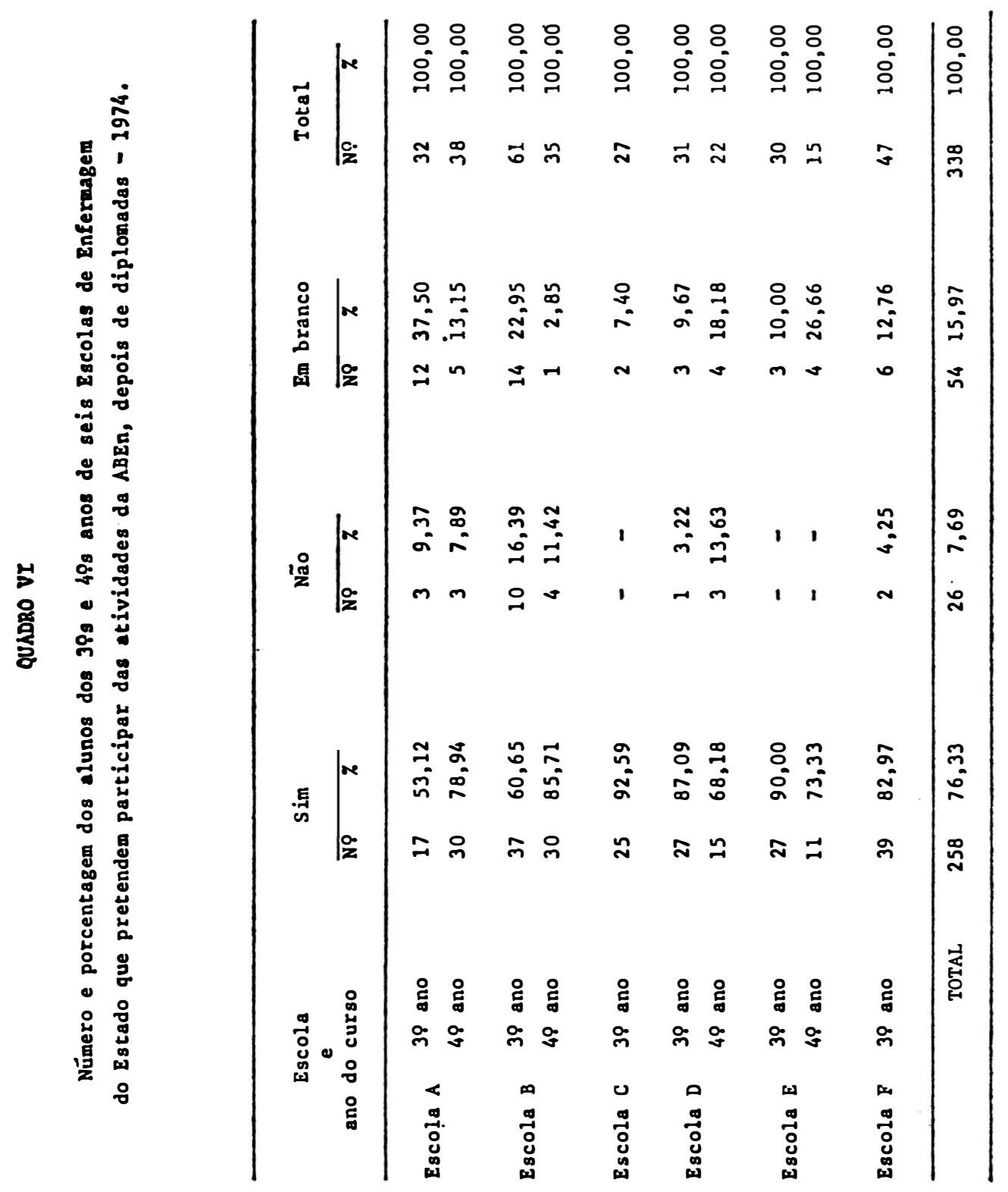




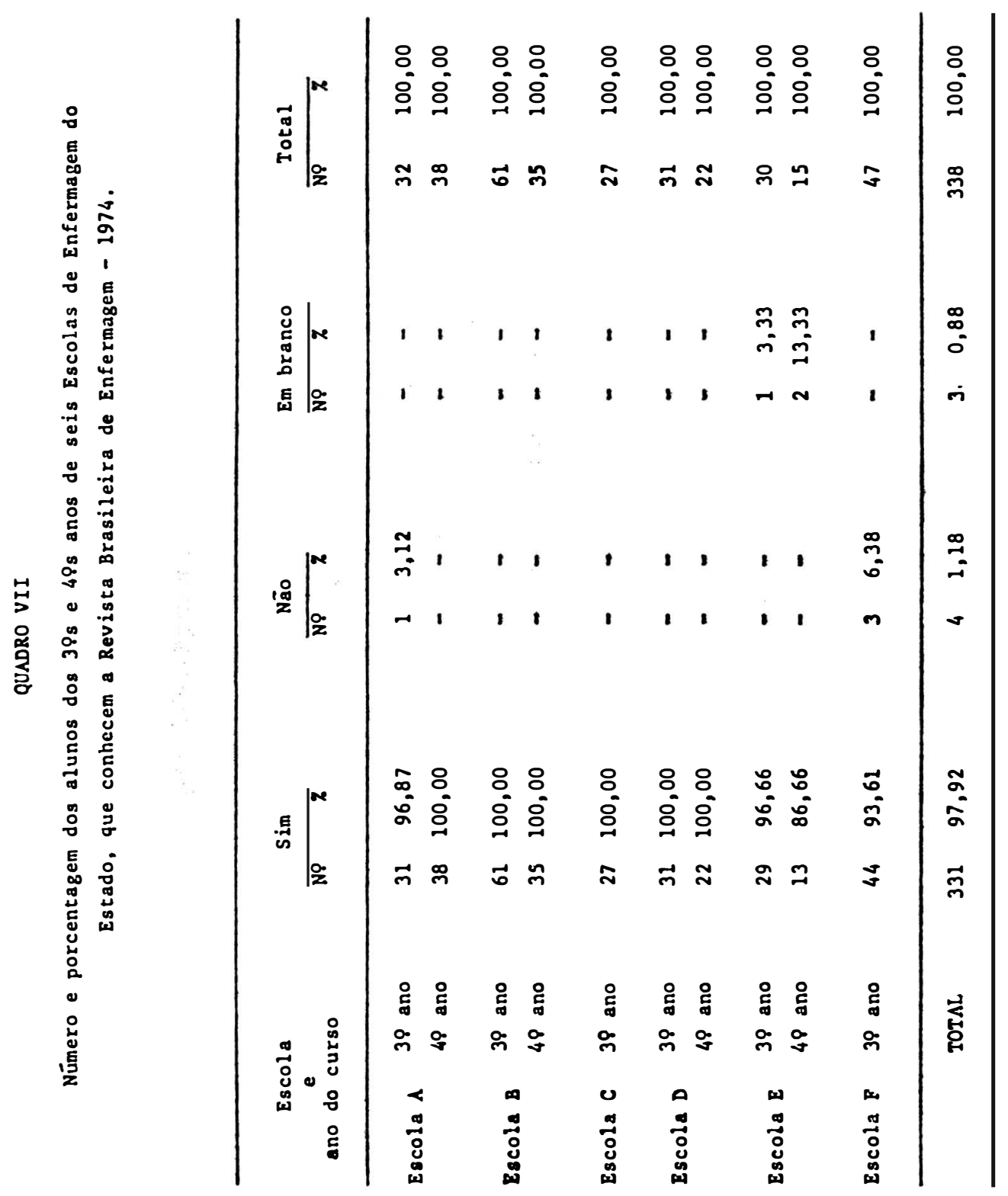




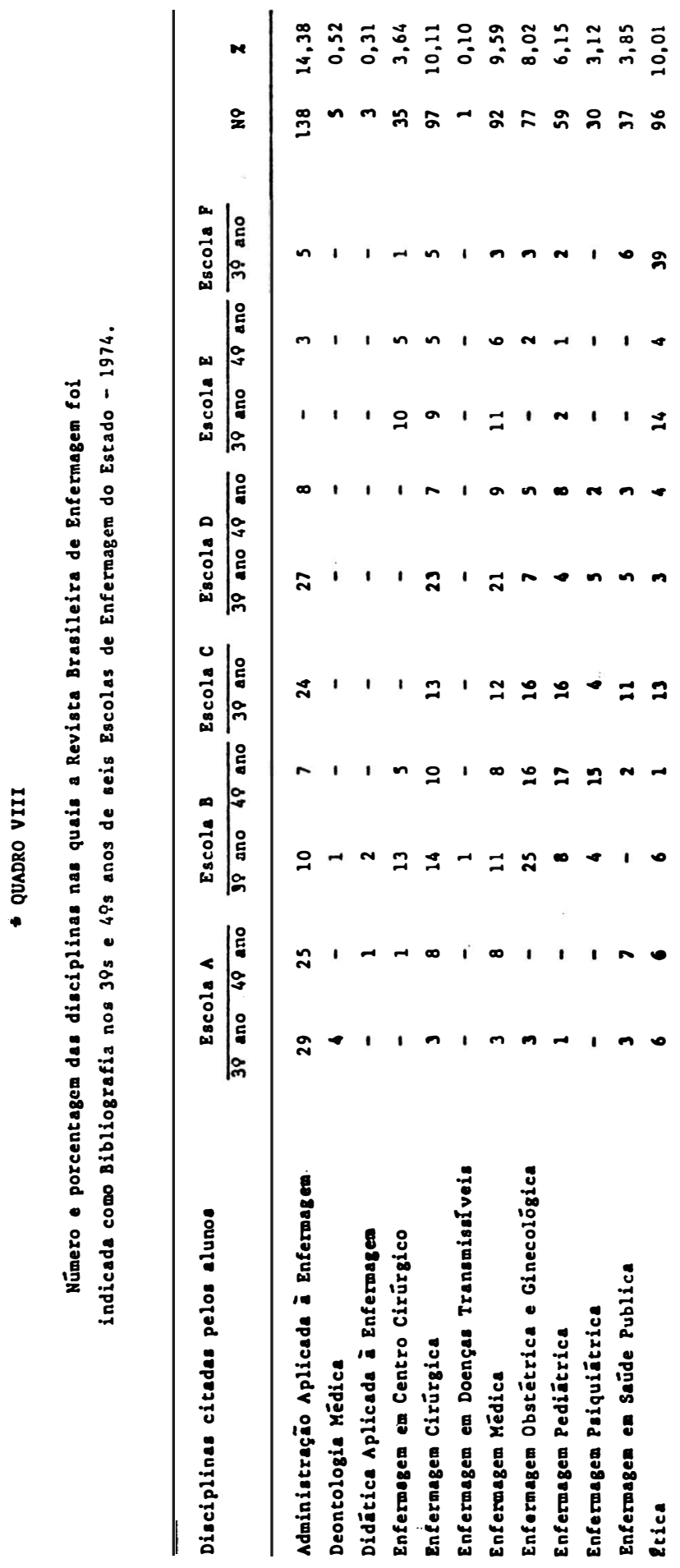




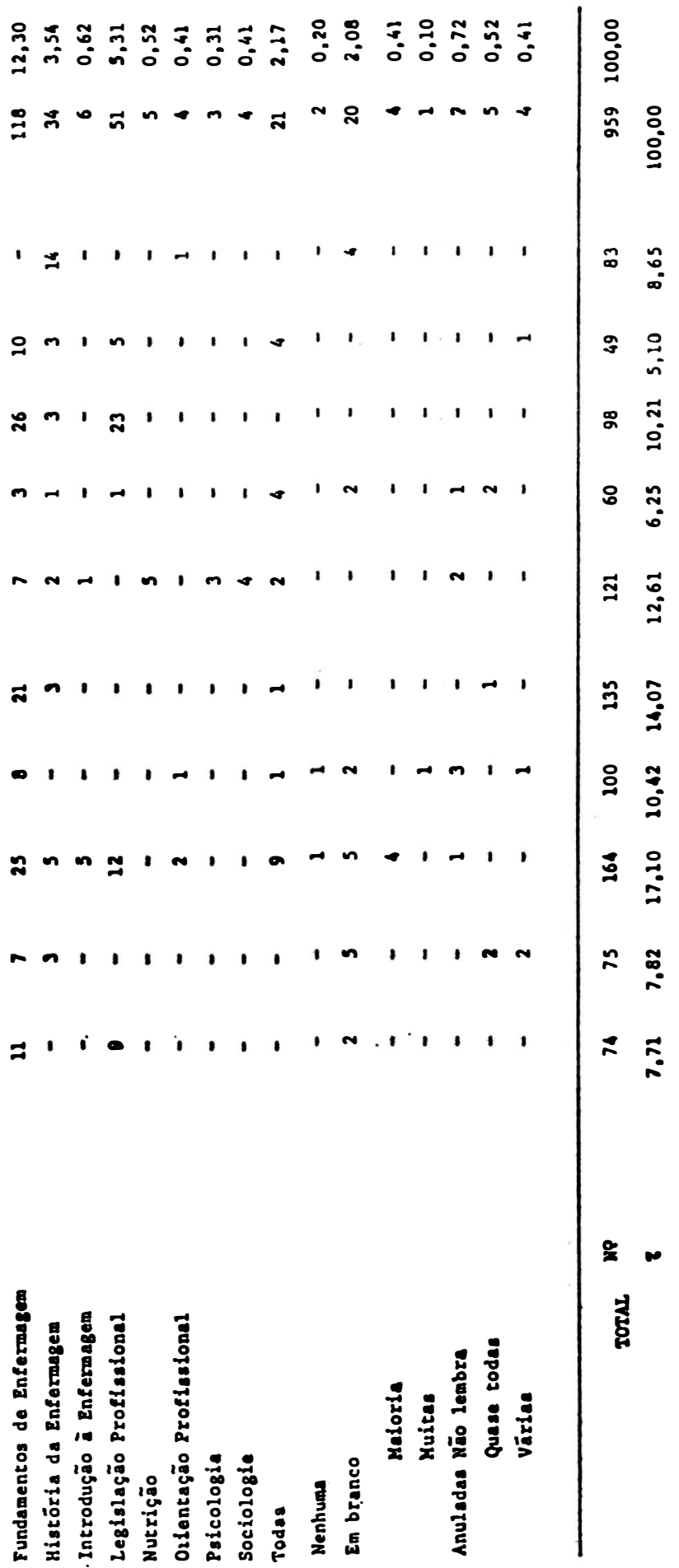


BURINI, M I. - "Estudo sobre a divulgação da Associaçāo Brasileira de Enfermagem (ABEn) no meio estudantil de Enfermagem". Rev. Bras. Enf.; DF, 29 : 127-157, 1976.

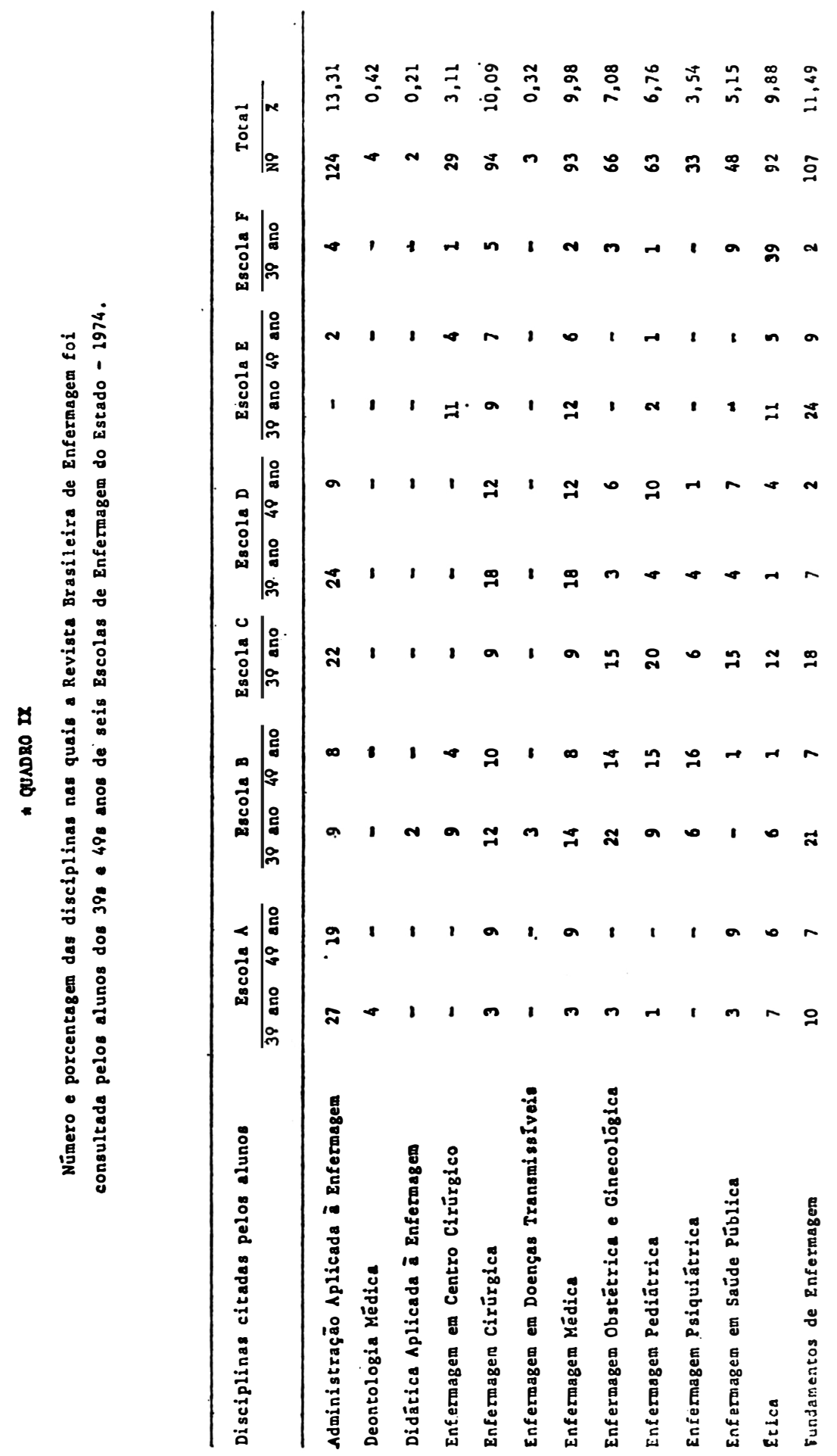




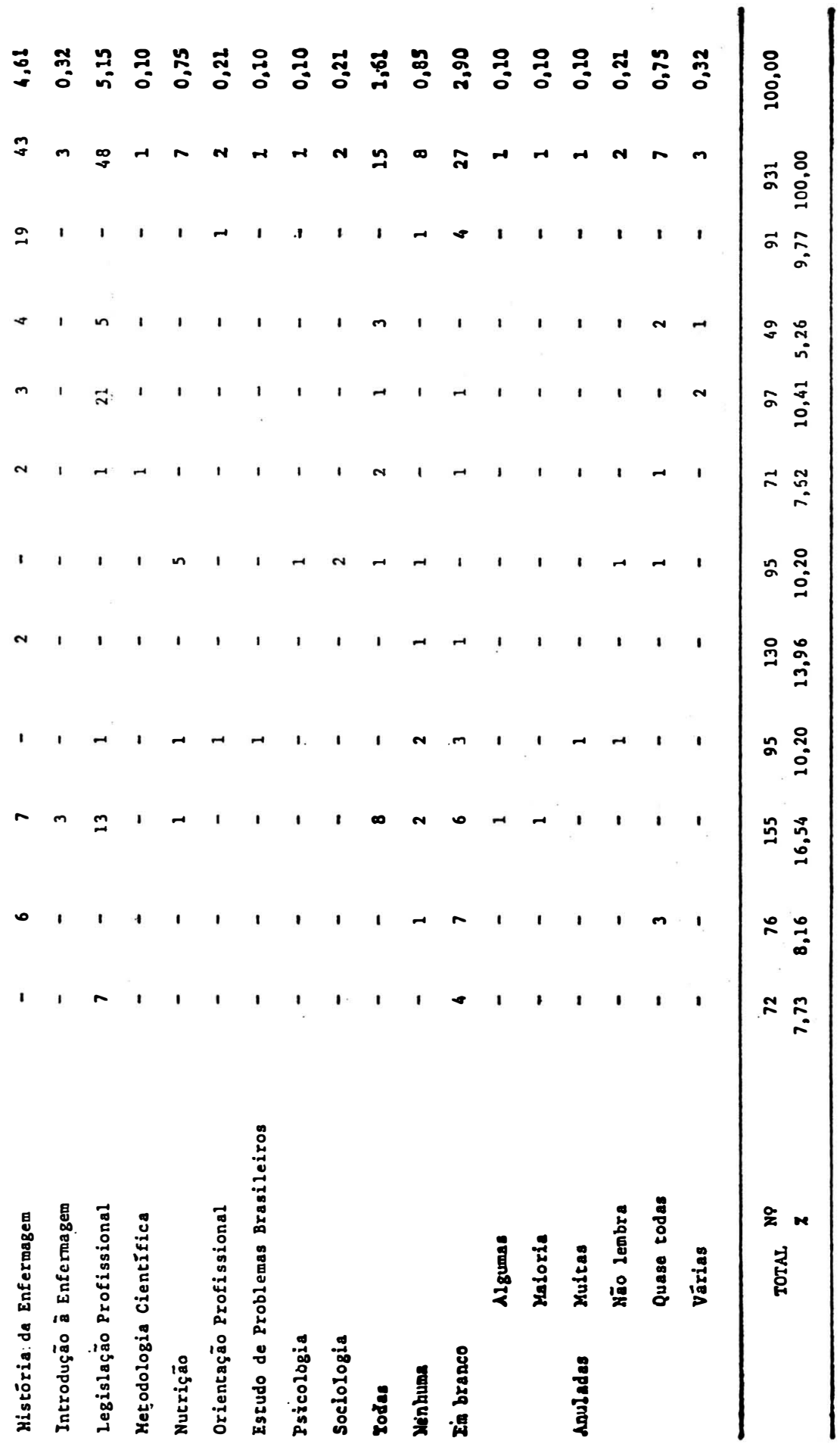




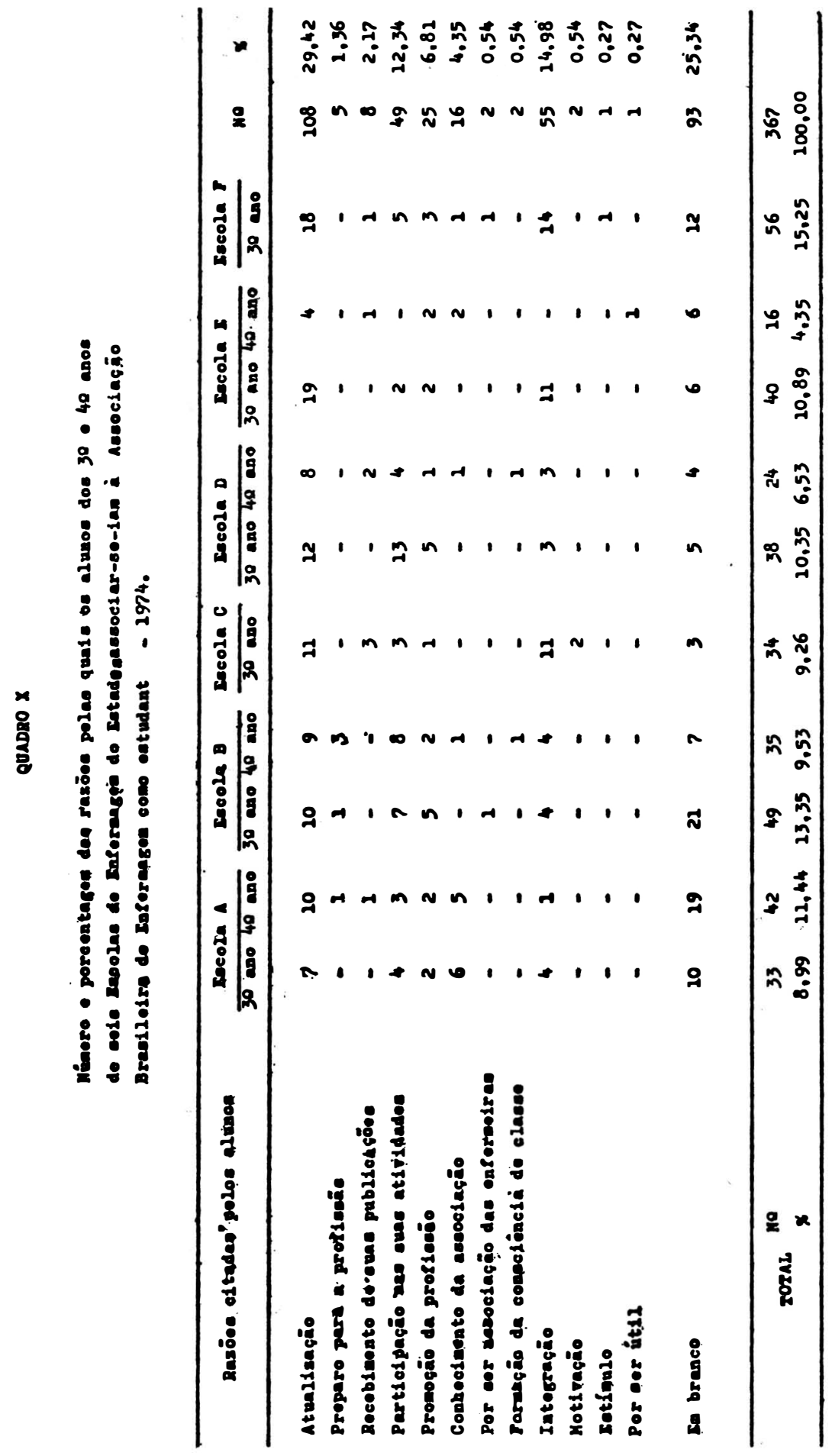




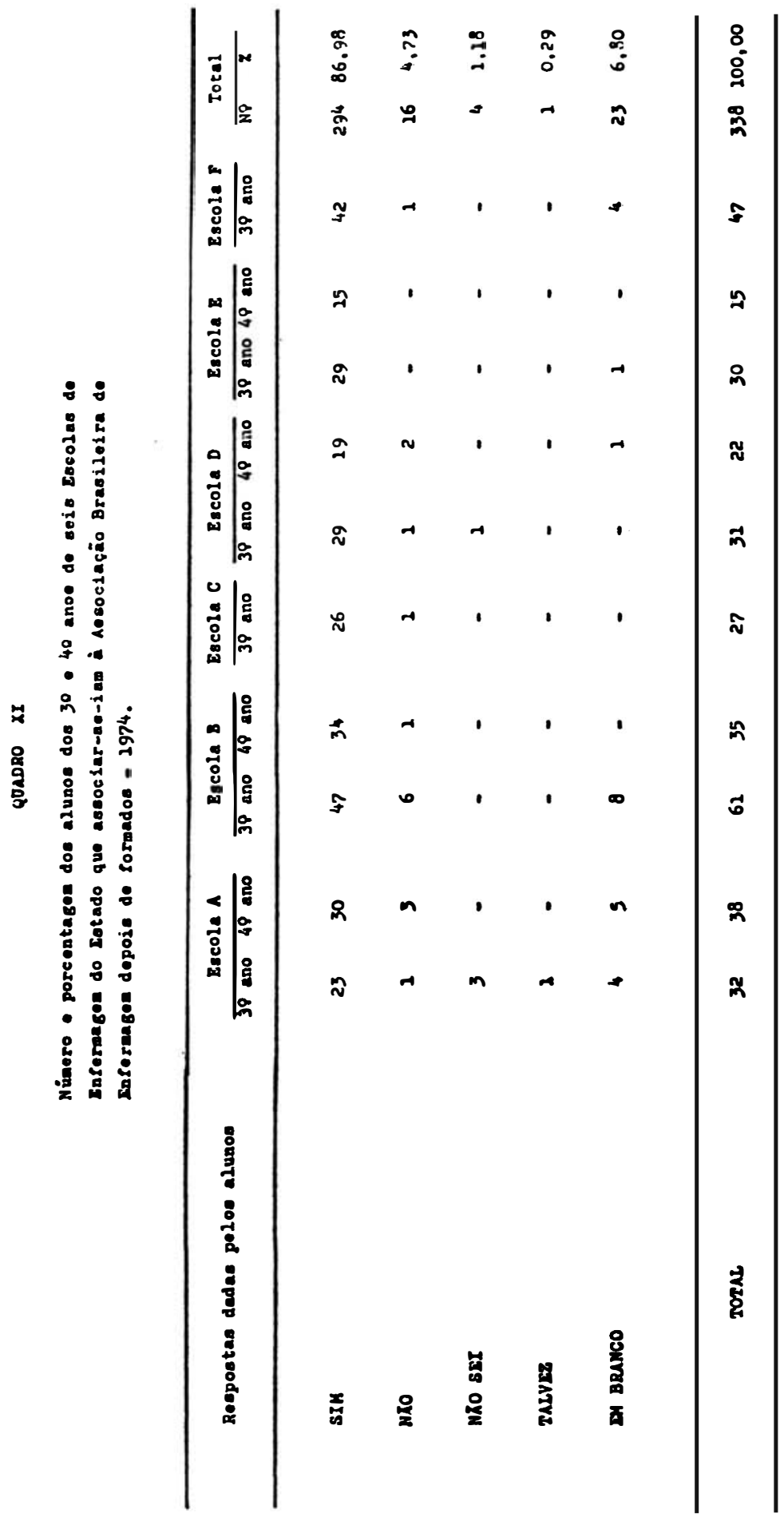




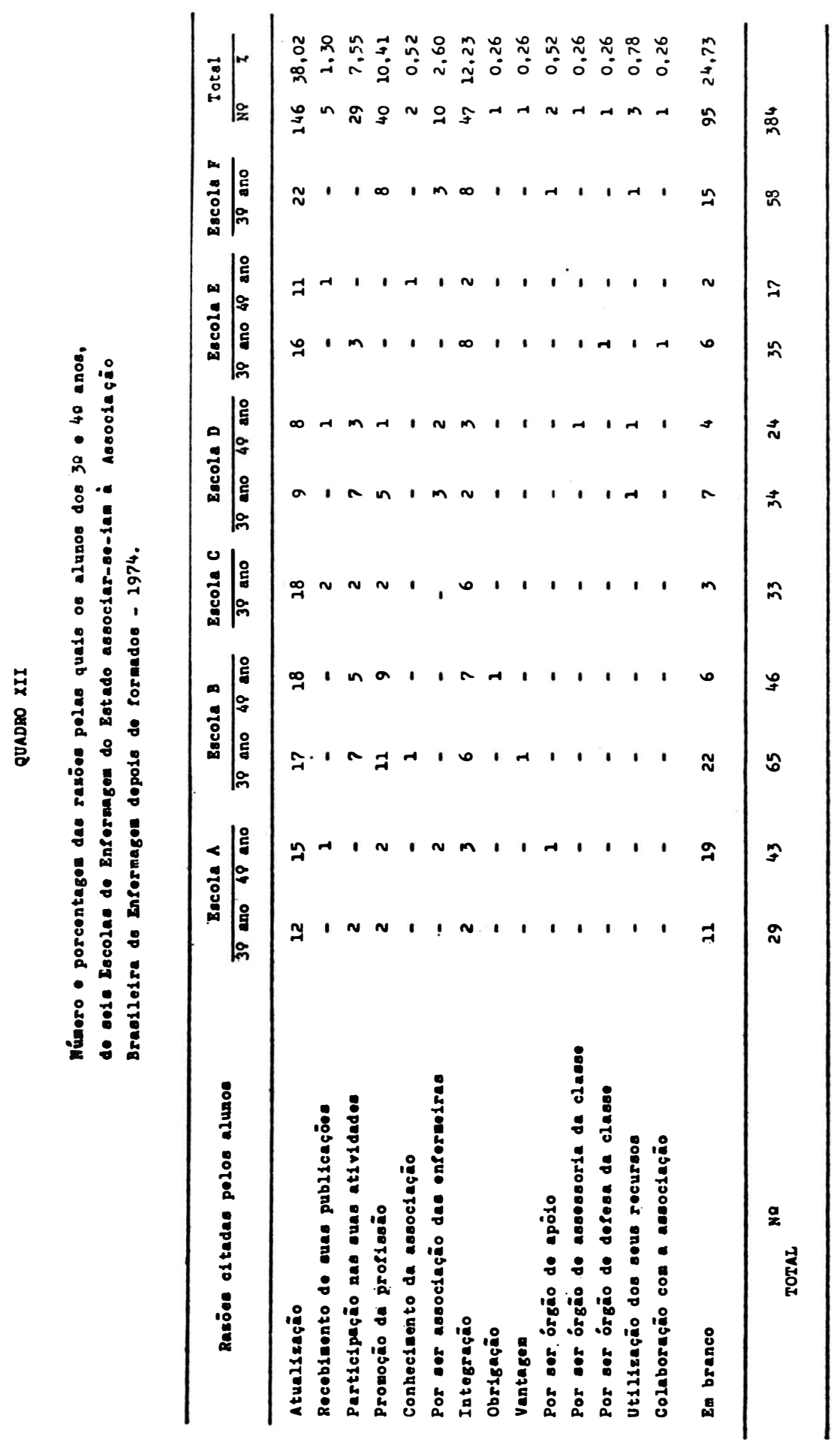


BURINI, M.I. - "Estudo sobre a divulgação da Associação Brasileira de Enfermagem (ABEn) no meio estudantil de Enfermagem". Rev. Bras. Enf.; DF, $29: 127-157,1976$.

\section{REFERENCIAS BIBLIOGRAFICAS}

1. ARAUJO, M. L - O valor do Diretório Académico nas Escolas de Enfermagem. Rev. Bras. Enf., 18 (4): 45664, out. 1965.

2. BRASIL. Leis, Decretos, etc. - Decreto n. ${ }^{\circ}$ 31.417, de 9 de setembro de 1952 - Declara de utilidade pública a Associação Brasileira de Enfermeiras Diplomadas. Díario Oficial, Rio de Janeiro, 11 de setembro de 1952.

3. CARVAlHo, A.C. de - Politica de trabalho da Associação Brasileira de Enfermagem. Rev. Bras. Enf., 15 (1 e 2): 146-152, Jan./abr., 1972.

4. DI LASCIO, C.M.D.S. - Preparo no curso de graduação para a integração de enfermeiro recém graduado na vida profissionol. Rev. Bras. Enf., 23 (3, 4, 5 e 6): 57-75, jul./dez., 1970.

5. EDITORIAL. Anais Enf., 16 (22): 3-4, jan./mar, 1947.

\section{BIBLIOGRAFIA}

1. ASSOCIACXO BRAS. ENF./COMISSAO DE DOC. E ESTUDOS - Dados sobre a formação do pessoal de enfermagem no Brasil, publicado peia ABEn, 1969.

2. CaRVALHO, A. C. de \& RIBEIRO, C. de M. - Declaração de princípios. Rev. Bras. Enf., 22 (1, 2 e 3): 214-221, jan./Jun., 1969.

3. CARVALHO, A.C. de - Relatório da presidente. Rev. Bras. Enf., 23 (3, 4, 5 e 6) : 149-168, jul./dez., 1970.

4. CaRvalHo, A. C. de - Relatório da presidente da ABEn. Rev. Bras. Enf., 24 (5): 208-231, jul./set., 1971.

5. CARVALHO, Anayde C. de - Aperfeiçoamento da enfermeira em cursos de pós-graduação. Rev. Bras. Enf., 18 (4): 318 e 320, out. 1965.

6. $\ldots \ldots \ldots \ldots-$ A formação do pessoal de enfermagem no Brasil. Relatório da Comissão de Documentação e Estulos da ABEn. Rev. Bras. Enf., 23 (3, 4, 5 e 6) : 179-189, jul./dez., 1970.

7. $\ldots \ldots \ldots \ldots-$ A Associação Brasileira de Enfermagem e sua contribuição para o desenvolvimento do ensino de Enfermagem no Brasil. Rev. Esc. Enf. USP, 8 (1): 45-123, 1974.

8. CARVALHO, J. F. de \& LOZIER, H. Base para a política da ABEn. Rev.
6. IMPERIAL, M.G.S.C. - Associação Brasileira de Enfermagem. Relatório da 1. Vice-Presidente - Presidente em exercício à Assembléía de Delegados. Rev. Bras. Enf., 28 (3) : 71-84, jul./set., 1975.

7. MEDEIROS, N. da R. D. de - Relatório da Comissão le Documentação e Estudos da ABEn - 1974/75. Rev Bras. Enf., 28 (3) : 85-109, jul./set., 1975.

8. OLIVEIRA, M.W.R. de - PREPARO NAS ESCOLAS DE ENFERMAGEM PARA A VIDA ASSOCIATIVA. Rev. Bras. Enf., 26 (3, 4, 5 e 6): 100-102, jul./dez. 1970.

9. RECOMENDAÇAO apresentada no Congresso Brasileiro de Enfermagem, 25, Joāo Pessoa, 15 a 21 de julho, 1973. Rev. Bras. Enf., 26 (1 e 2): 349, 1973.

10. RESENDE, M. de A. - Histórico da Revisto Brasileira de Enfermagem. Rev. Bras. Enf., 15 (6) : 496-515, dez., 1962.

\section{CONSULTADA}

Bras. Enf., 22 (1, 2 e 3): 222-234, jan./jun., 1969.

9. DOURADO, H. G. - Editorial: A ABEn contribui para uma melhoria definitiva na enfermagem. Rev. Bras. Enf., 18 (5) : 483-4, dez., 1965.

10. EDITORIAL - A ABEn e os congressos. Rev. Bras. Enf., 15 (4) : 231-232, ago., 1962.

11. HEREDIA, M.E.M. \& VIEIRA, H.A. - O espírito associativo e o enfermeiro no Rio de Janeiro. Rev. Bras. Enf., 28 (1) : 78-83, jan./mar., 1975.

12. IMPERIAL, M.G.S.C. - Preparo no campo de trabalho para a vida associativa. Rev. Bras. Enf., 26 (3, 4, 5 e 6): 103-8, jul./dez., 1970.

13. JAHODA, Marie - Una psicóloga social considera la enfermera como professión. Recopilacion de Trabajos. Publicaciones Científicas n. ${ }^{\circ} 78$ OPAS/OMS, Whashington, 1963.

14. RESENDE, M. de A. - Significação da vida associativa em Enfermagem. Rev. Bros. Enf., 10 (4): 375-394, dez., 1957.

15. ........ - Sobre a ABEn. Rev. Bras. Enf., 14 (4) : 385-389, ago., 1961.

16. ........ - Literatura profissional e estudantes de Enfermagem. Rev. Bras. Enf., 17 (3 e 4) 128-134, jun.) ago., 1964. 
BURINI, M.I. - "Estudo sobre a divulgação da Associação Brasileira de Enfermagem (ABEn) no meio estudantil de Enfermagem". Rev. Bras. Ene.; DF, 29 : 127-157, 1976.

\author{
ANEXO I \\ ESCOLA DE ENFERMAGEM DA UNIVERSIDADE DE SAO PAULO \\ QUESTIONARIO
}

ESCOLA:

IDADE:

SEXO:

NACIONALIDADE:

NATURALIDADE:

STRIE DO CURSO:

NOTA: Assinale com um $\mathrm{X}$ a resposta que achar mais conveniente e, nas perguntas em que não houver opções, escreva o que, em sua opinião achar melhor, utilizando para isso o espaço em branco em baixo da pergunta.

1. Existem associações de classe como: Sindicatos, Associação Médica Brasileira, etc. Voce sabia que os enfermeiros se agrupam formando a ABEn (Associação Brasileira de Enfermagem)?

Sim: - Não:

2. Ficou sabendo disso:
a) antes de entrar na escola de enfermagem:
b) no 1.0 ano:
c) no 2.0 ano:
d) no 3.0 ano:
e) no 4.0 ano:

3. Conheceu a ABEn através de:

a) professor de: legislação:

ética:

administração:

orientação profissional:

história da enfermagem: 
b) Congresso Brasileiro de enfermagem:

c) Revista Brasileira de enfermagem:

d)

4. Quais as atividades da ABEn que são de seu conhecimento?

j. Voce pretende participar de alguma atividade da ABEn, futuramente?

Sim:

Não:

Por que?

i. Voce conhece a Revista Brasileira de Enfermagem?

Sim:

Não:

7. Consulta-a:

habitualmente:

esporadicamente:

nunca:

8. Caso voce se formasse este ano, gostaria de associar-se a ABEn?

Sim:

Não:

9. Que vantagens traria para você?

10. E desvantagens?

11. Se, por um motivo qualquer, não pudesse agora, associar-se-ia no futuro?

Sim:

Não:

Diante de resposta negativa, por que? 
BURINI, M.I. - "Estudo sobre a divulgaçāo da Associaçāo Brasileira de Eñerermagem (ABEn) no meio estudantil de Enfermagem". Rev. Bras. Enf.; DF, 29 : 127-157, 1976.

\section{ANEXO II \\ LEVANTAMENTO DE DADOS SOBRE A DIVULGAÇAO DA ASSOCIAÇAOO BRASILEIRA DE ENFERMAGEM NO MEIO ESTUDANTIL}

\section{QUESTIONARIO}

O propósito deste estudo é fazer um levantamento do conhecimento que os alunos dos terceiros e quartos anos das Escolas de Enfermagem do Estado tèm sobre a Associação Brasileira de Enfermagem (ABEn).

A identificação do questionário é desnecessária e agradecemos sua valiosa colaboração.

ESCOLA:

STRIE DO CURSO:

IDADE:

SEXO:

NACIONALIDADE: NATURAL DE:

INSTRUÇOES: assinale com um $\mathrm{X}$ a resposta que achar mais conveniente. Onde não houver opções, responda a pergunta utilizando o espaço abaixo da mesma.

1 - Na sua Escola a associação estudantil recebe o nome de:
a) Centro Acadêmico
b) Diretório Acadêmico
c) Outro

2 - Qual ou quais são suas finalidades?

3 - Voce participa das suas atividades? SIM - NAO -

4 - Voce sabe que as enfermeiras têm uma associação de classe com o nome de ABEn? SIM NAO

5 - Ficou sabendo disso:

a) Antes de entrar na Escola de Enfermagem

b) No $1 .^{\circ}$ ano 

c) No 2.0 ano
d) No $3 .^{\circ}$ ano
e) No $4^{\circ}$ ano

6 - Conheceu a ABEn através de:

a) Professor de: Legislação

Etica

Administração

Orientação Profissional

História da Enfermagem

Citar outros

b) Congresso Brasileiro de Enfermagem

c) Revista Brasileira de Enfermagem

d) Cite outro processo não enumerado

7 - Quais as atividades da ABEn que você:

conhece -

participa -

8 - Pretende participar de alguma futuramente? SIM — NAO —

9 - Conhece a Revista Brasileira de Enfermagem? SIM — NAO -

10 - Em quais disciplinas a Revista foi indicada como bibliografia?

11 - Em quais disciplinas voce a consultou?

12 - Estaria interessada(o) em associar-se à ABEn como estudante, se isto fosse possível? SIM — NAO —

POR QUE?

13 - Pretende associar-se à ABEn depois de formada(0)?

SIM - NAO -

POR QUE? 